\title{
The Dual Pricing of Destinations: Tourist Perception on Sri Lanka
}

\author{
Kingsley Bernard ${ }^{1}$, Chamud Sathyapala ${ }^{1}$, Thusara Wijesuriya ${ }^{1}$, Sahan Sachintha ${ }^{1}$, Rajith Dhanushka ${ }^{1}$ \\ ${ }^{1}$ SLIIT Business School, Sri Lanka Institute of Information Technology, New Kandy Road, Malabe, Sri Lanka \\ Correspondence: Dr. D. T. Kingsley Bernard, Senior Lecturer, SLIIT Business School, New Kandy Road, \\ Malabe, Sri Lanka.
}

Received: June 5, 2020

doi:10.5539/ibr.v13n8p18

\author{
Accepted: July 3, $2020 \quad$ Online Published: July 21, 2020 \\ URL: https://doi.org/10.5539/ibr.v13n8p18
}

\begin{abstract}
Dual-Pricing of entrance fees to tourist destinations is a sensitive current issue among travelers, industry experts, and policy developers. This practice is mostly observed in the global south countries, to which Sri Lanka belongs. This study focuses on identifying and measuring the factors that influence the willingness-to-pay (WTP) entrance fees by foreign tourists visiting Sri Lanka and to understand their perception of the concept. The findings of this study revealed that income, knowledge, perceived price fairness, and visitor expectations possessed a significant relationship with WTP entrance fees in a dual-pricing context. Excepting knowledge other three variables had a significant impact on WTP. Furthermore, it was revealed that a majority of tourists accepted the dual-pricing policy, subject to certain concerns.
\end{abstract}

Keywords: dual-pricing, willingness-to-pay, perception, foreign tourists, Sri Lanka

\section{Introduction}

The global travel and tourism industry is considered to be one of the world's largest industries with an overall economic contribution of over 2.9 trillion USD to Global GDP in 2019 (World Tourism Organization (WTO), 2020). The statistics on global tourism suggest that Europe had received the most number of tourists by region, whilst the highest expenditure on international travel and tourism was recorded by China followed by the United States (Sri Lanka Tourism Development Authority(SLTDA), 2019). Given the fact that how lucrative the industry is, the attractions around the world are primarily divided into two geographical areas based on the economic strength of the countries, namely, Global North countries and Global South countries. Out of these two regions, the case of 'dual pricing' (DP) on entrance fees at tourist attractions, is a current and a topical issue which is a widely discussed subject in the latter region.

The term 'dual pricing' in tourism, at a glance, is not very familiar to local or foreign visitors, especially among the foreign visitors, since this concept does not operate in most of the developed western nations. Neither, do the locals know much about this policy, except the fact that they are charged a lesser fee to enter the various tourist attractions. Thus, the concept of 'dual pricing' or differential pricing in generic terms is a pricing policy where different segments of a market, in simple terms where foreigners and locals are charged different rates to experience the same product or service. Moreover, dual pricing is not just based upon the concept of residents and non - residents but can be implemented via a practice of charging differential prices (i.e. two separate prices in this case) in different market segments for the same product or service. Hence dual pricing is a concept that is not defined based only on being residents and non-residents but under various categorizations such as, students, researchers, nationals, and foreigners. Thus, governments who are promoting tourism employ different pricing strategies for these categorized groups. Howard (2009) has discussed that there are both pros and cons in this context, as the willingness of the tourists to travel to a place is highly dependent on the cost of the destination.

Sri Lanka is a country that thrives on tourism and would strive to gain its maximum benefits, wherein $14.8 \%$ of annual total foreign earnings are generated through the industry in the discussion (SLTDA Annual Report, 2019). Therefore, the focus on dual pricing and its impact on the overall tourist attraction towards the country is in-depth discussed. Specifically, when Sri Lanka recorded a total foreign tourist inflow (travelers) of 1,913,702 in 2019, 82\% visited for leisure and holiday (SLTDA Annual Report, 2019). The island nation is home to a wide range of tourist attractions, which can offer experience and enjoyment to both the locals and foreigners visiting these sites. Such sites include national parks, museums, cultural triangle sites, botanical gardens, forest reserves, historical sites, and temples in religious sites. Similar to the pricing policy adopted by the regional counterparts/ 
neighboring countries in the region, most of these locations charge a relatively higher entrance fee for foreign visitors but allows free or subsidized-fee access to local visitors. However, the discussion on dual pricing is often of two folds. In many instances, from a service provider's standpoint, it is justified with the notion of letting their sites to be explored by the non-residents. From the viewpoint of foreigners, they are willing to pay a price for the visits but felt they are being over-charged, which is often discussed as a discouraging fact (Howard 2009). As such, this DP concept is highly important to Sri Lanka.

Moreover, the recent trends in the flow of tourists to the island show that there is an increase in the number of youth traveling to Sri Lanka and also a higher percentage of Chinese travelers among the visitors (SLTDA Annual Report, 2019). Considering these statistics, more youth travelers imply that their spending capacity is relatively lesser as opposed to a traveler of middle age or a person in his fifties. This has been a trend seen in many parts of the world, and Sri Lanka is no exception. Pearce (2005) has noted the behavior surrounding the tourists, that when it comes to choosing a destination, it is about having a rich experience. Hence, they intend to choose a few places and then engage in finding a richer experience. In this context, the tourist sites are a particularly important selection criterion for the tourists. Therefore, if these are high priced, it reduces the overall quality of experience. Customer dissatisfaction will lead to a lesser number of tourists visiting these sites. However, the Asian region is often perceived as an inexpensive destination. Further, it is important to understand that Sri Lanka is not a tourist destination that is visited by a majority of rich, extravagant travelers but the average spenders (SLTB Annual Report, 2019). As a result, the case of dual-pricing may have a greater impact in the years to come especially with the expected negative impact on the global economic and social conditions due to COVID 19 epidemic. In this context, the primary focus of this paper is regarding the foreign tourist's willingness-to-pay (WTP) entrance fees at tourist destinations in Sri Lanka under the dual-pricing policy and to gain an understanding of tourist perception of adopting such a pricing mechanism in Sri Lanka.

Table 1. Countries using Dual-pricing system

\begin{tabular}{lllll}
\hline Country & Tourist facility & $\begin{array}{c}\text { Local people } \\
\text { (USD) }\end{array}$ & $\begin{array}{l}\text { Foreign tourist } \\
\text { (USD) }\end{array}$ & $\begin{array}{c}\text { Percentage } \\
\text { difference }\end{array}$ \\
\hline India & Taj Mahal & 0.4 & 14 & $3400 \%$ \\
Kenya & Fort Jesus & 2.5 & 9.5 & $280 \%$ \\
Peru & Machu Picchu & 25 & 49 & $196 \%$ \\
Thailand & Bangkok Museum & 3.5 & 7 & $200 \%$ \\
Iran & Persepolis & 0.5 & 12 & $2300 \%$ \\
Indonesia & Borobudur & 3 & 20 & $566 \%$ \\
Zimbabwe & Victoria Falls & 7 & 30 & $328 \%$ \\
Seychelles & Vallee de Ma & 1 & 27 & $2600 \%$ \\
Ecuador & Galapagos Park & 6 & 100 & $1566 \%$ \\
\hline
\end{tabular}

Source: Apollo (2014)

Table 2. Destinations with Dual-pricing in Sri Lanka

\begin{tabular}{llll}
\hline Destinations & Local (LKR) & Foreigners (LKR) & Difference (\%) \\
\hline Sigiriya Rock Fortress & 50 & 5250 & $10400 \%$ \\
Pinnawala Elephant Orphanage & 110 & 3000 & $2627 \%$ \\
Temple Kandy & No charge & 1500 & huge \\
Peradeniya Botanical Gardens & 110 & 2000 & $1718 \%$ \\
Yala National Park & 200 & 2500 & $1250 \%$ \\
National Zoological Garden & 110 & 3000 & $2627 \%$ \\
Horton Plains - Nuwara Eliya & 200 & 3000 & $1400 \%$ \\
Dambulla Cave Temple & No charge & 1500 & huge \\
\hline
\end{tabular}

Source: Sri Lanka Tourism Development Authority (2019).

Table 1 shows that there is a substantial difference between what the tourist and a local is paying to enter into a tourist site around the world. Table 2 further confirms the same situation in Sri Lanka. This leads to two major disadvantages; one is that when these discrepancies are noted - some tourists have become reluctant to visit these places. On the other hand, many foreign tourists have appreciated the fact that they must pay a fee to enter into different historical and other important sites in the destination country (Walpole et al, 2011). However, if they are paying the premium prices - they look forward to better and quality infrastructure. This has been an issue in Sri Lanka where many tourists have complained about the lack of facilities at the destinations. 
Especially many travel bloggers and independent viewers have discussed and pointed out the fact that there is far lesser tourism-friendly infrastructure in Sri Lanka, specifically when it comes to amenities such as washrooms, and changing rooms. In terms of the Sri Lankan tourist sites - it shows that there is a huge gap between what is expected with a fee - and what is delivered to the tourists. Hence, the purpose of high fees is also not justified.

Dual-pricing is an issue and also a matter of concern not only in Sri Lanka but in the South Asian region as well. Countries such as Thailand have legalized DP, charging fees from tourists when they are receiving public health care services (Bangkok Post, 2012). However, there is a concern about the ethical aspect. Moreover, Nepal is also one of the countries which have legalized DP on residents and non-residents. Thus, the legalization of these aspects has created a concern for the tourists who visit these countries. Nevertheless, the DP issue remains the same on the ground of rationalization. Some scholars such as Howard (2009) stated, that there is rationalization because most of the dual pricing is seen in the developing countries. As a result, these nations rely heavily on tourism and thus, needs to gain the maximum benefits that can be derived from a foreign traveler.

In terms of business ethics and corporate governance, the high prices/premium prices should be charged based on the level of service. Hence, if the dual pricing system is to be implemented - there needs to be a higher quality of service. However, the focus should also be on the foreign traveler's perspective. If the latter are willing or unwilling to pay - they (foreign travelers) should have a choice, especially with regards to knowing ahead of the facilities that they will be offered with the high prices charged. Henceforth, this creates a substantial research opportunity to analyze and discuss the concept of dual pricing and as to the willingness of these foreign travelers to pay the price, especially concerning ethical, economic, and social aspects. Hence, this research has built upon scholarly findings of several other researchers conducted in countries such as Thailand, Nepal, and Iran - which also carries the same principle towards foreign travelers.

Firstly, the study identifies the variables that determine the willingness-to-pay dual-priced entry fees in the Sri Lankan context. Which are Income, Knowledge, Perceived Price Fairness, and Visitor Expectations and the relevant conceptual framework will be established? Secondly, the study evaluates the relationship of the Independent variables with the dependent variable which is WTP.

Thirdly, the research evaluates the impact of the identified variables on Willingness to pay entry fees in a dual-pricing condition which revealed that Income, Perceived Price Fairness, and Visitor Expectations have had a significant impact on determining the WTP in the given context, while Knowledge was not making a significant impact on WTP when tested collectively. Thus, in this study context, the dominant influencers were only three out of the four variables tested, as opposed to literature based on other countries.

Finally, the study facilitated understanding the perception of foreigners on the dual-pricing policy and its implementation. Hence, it will contribute to the theory, knowledge, policy, and practice. Further, as a result of a post-COVID impact on the economies of other countries, attracting tourists to Sri Lanka would be much harder than it was, hence analyzing this problem would be of high priority to Sri Lanka.

\section{Materials and Methods}

\subsection{Research Problem}

The research problem takes into consideration under this study is the Impact of Dual-pricing policy adapted at tourist destinations on the Willingness-to-pay (WTP) of foreign travelers in Sri Lanka. A dual-pricing system in tourism services refers to the practice of setting two separate prices for residents and non-residents (Sharifi-Tehrani et al., 2013), in which non-residents are asked to pay higher prices than residents. More specifically, this research ponders on the tourist destinations in Sri Lanka that issue a ticket, or rather charge an entrance fee to experience the respective attraction, where foreigners are charged a substantially higher price than the locals.

The rationale for imposing dual-pricing strategy on cultural attractions, such as museums in developing countries, is assumed to be results of believing that tourists from more developed countries have a higher household income than the earnings of host country residents and that tourists do not pay taxes (Sharifi-Tehrani et al., 2013).

Although, one might assume that exchange rates would cancel out any unacceptable effect of dual-pricing, which is true to a certain extent. DP can generate negative word of mouth and could build criticisms that may hamper the image of Sri Lanka as a top-class tourist destination.

The issue of Dual-pricing is more prevalent in the 'Global South countries', in which Sri Lanka is a part of. Studies on similar areas have been conducted in different geographical locations, such as Costa Rica, the United States of America, Iran, Nepal, and many other countries. However, previously documented research available to 
date has not been based on a study of this nature, applied in the Sri Lankan context.

Thus, there prevails a knowledge gap that needs to be addressed in this study. It is evident now that the issue on the concept of dual-pricing has not been tested in Sri Lanka before (as per available information and sources), and most importantly that the willingness-to-pay and factors influencing it, in terms of foreign tourists to the country. In the context of the post-COVID economic impact on Sri Lanka being a country earning approximately $15 \%$ of its foreign exchange earnings from tourism, the research problem identified would be of great concern.

\subsection{Research Objectives}

1. To determine the variables that affect foreign traveler's willingness-to-pay entrance fees at tourist attractions.

2. To identify the relationship between each variable with willingness-to-pay.

3. To evaluate the impact of the identified variables on willingness-to-pay by foreign travelers in Sri Lanka.

4. To understand the perception of foreign tourists on the dual-pricing concept and its application.

\subsection{The Hypothesis of the Study}

Currently, tourism has become a major influencer in the economy of many developing countries. The travel and tourism industry is a vast sector that can be categorized into many segments based on the destination, such as eco-tourism, adventure and leisure, and culture \& heritage.

Many facilities used by tourists are public goods or are supported by a mix of revenue streams arising from both the private and public sectors, for example, parks, beaches, museums, gardens, etc. (Wu et al., 2014). Moreover, $\mathrm{Wu}$ et al. (2014) state that whether to charge or not for the use of public goods and if so, how much to charge are questions that have been under discussion over the years.

Dual-pricing refers to the practice of setting much higher prices for foreigners than for domestic visitors (Apollo, 2014). This kind of price differentiation, according to Apollo is a common problem in Global South countries which are still under the category of 'developing countries'. The reason for the aforementioned can be stated as developing countries hold the belief that tourists from developed countries have a higher household income (Reynisdottir, Song, and Agrusa 2008).

Past literature reveals information about knowledge and the feelings of price differences on entry fees at tourist facilities. The study conducted based on nine tourist destinations in Nepal in the year 2014 concluded that a relatively low (46\%) percentage of foreign travelers from the selected sample were aware of the price difference. Apollo (2014) states that a large percentage from the group under study held, that foreigners who have experienced differential pricing will convey about the price discrimination to their family and friends after returning home.

Differences in willingness-to-pay have been found to affect according to income, some previous visits, history of paying entrance fees, country of residence, age, and education (Reynisdottir et al., 2008). Thus, it has been emphasizing on the demographical aspects which also plays a vital role concerning the topic under discussion. Wu et al. (2014) in their research highlight the fact that to determine variables such as WTP, 'Contingent Valuation' studies, have been carried out to evaluate the effects of different admission fees, or to place a value on the benefits/non-market benefits acquired by users.

A study carried out based in 'West Lake, China' has shown that adaption of a free pricing policy for entrance to a majority of sites in the area, has impacted tourism positively with an increased flow of tourists. Thereafter, national survey results indicated that the area under consideration was one of the few places in China known to have high satisfaction among independent travelers and tourists. Furthermore, a comparison between the free-admission sites and fee-charging sites has shown that the free admission policy has stimulated growth in the number of tourists substantially (Wu et al., 2014). Sharifi-Tehrani et al. (2013) highlighted three variables attitude, distance, and involvement - which have deemed to be an important justification for implementing a dual-pricing strategy. Similarly, past literature elaborates that demographical factors such as age, gender, education, and knowledge level affect the willingness-to-pay. Besides, Murphy, Pritchard, and Smith (2000) elaborate on the 'Price-Value Perception model' of tourists which discusses the determinants i.e., reasonable price, satisfaction, value for money, country of origin, the season of visit, that would affect a tourist's intent to revisit the same destination. The proportion of the entrance fee within the composite price is likely to influence the purchase decision (Crompton \& Jeong, 2016). However, there is no clear evidence of documented material on the perception of dual-pricing, connecting the possible variables that would determine the willingness-to-pay of entrance fees in Sri Lanka. The following table (Table 3) summarizes the four independent variables which are 
considered in this study based on the literature survey in understanding the behavior of the dependent variable; willingness to pay by the tourists under a dual pricing policy.

Table 3. Summary of literature review for identifying variables

\begin{tabular}{lll}
\hline Variable & Author & Measurements and findings \\
\hline Income & Apollo (2014) & A strong positive relationship with \\
& Chung et al. (2011) & \\
& Reynisdottir et al. (2008) & \\
\hline Sharifi-Tehrani et al. (2013) & 5 point Likert scale \\
& Apollo (2014) & \\
& Reynisdottir et al. (2008) & A moderate positive relationship \\
& Sharifi-Tehrani et al. (2013) & WTP \\
\hline Perceived Price Fairness & Chung et al. (2011) & 5 point Likert scale \\
& Perdue (2002) & A strong positive relationship with \\
& Asadi et al. (2014) & WTP \\
& Petrick (2004) & \\
& Bolton et al. (2003) & 5 point Likert scale \\
& & A strong positive relationship with \\
& Khan (2003) & WTP
\end{tabular}

Source: Authors' compilation based on Literature

Thus, this literature survey shows the importance of carrying out this study and conceptualizing a model to address the problem, by converging the best-suited variables from literature. However, the area of study concerned in this research has been tested in different contexts. As such, the conceptual framework (Figure 1) is derived from past literature in the Sri Lankan setting.

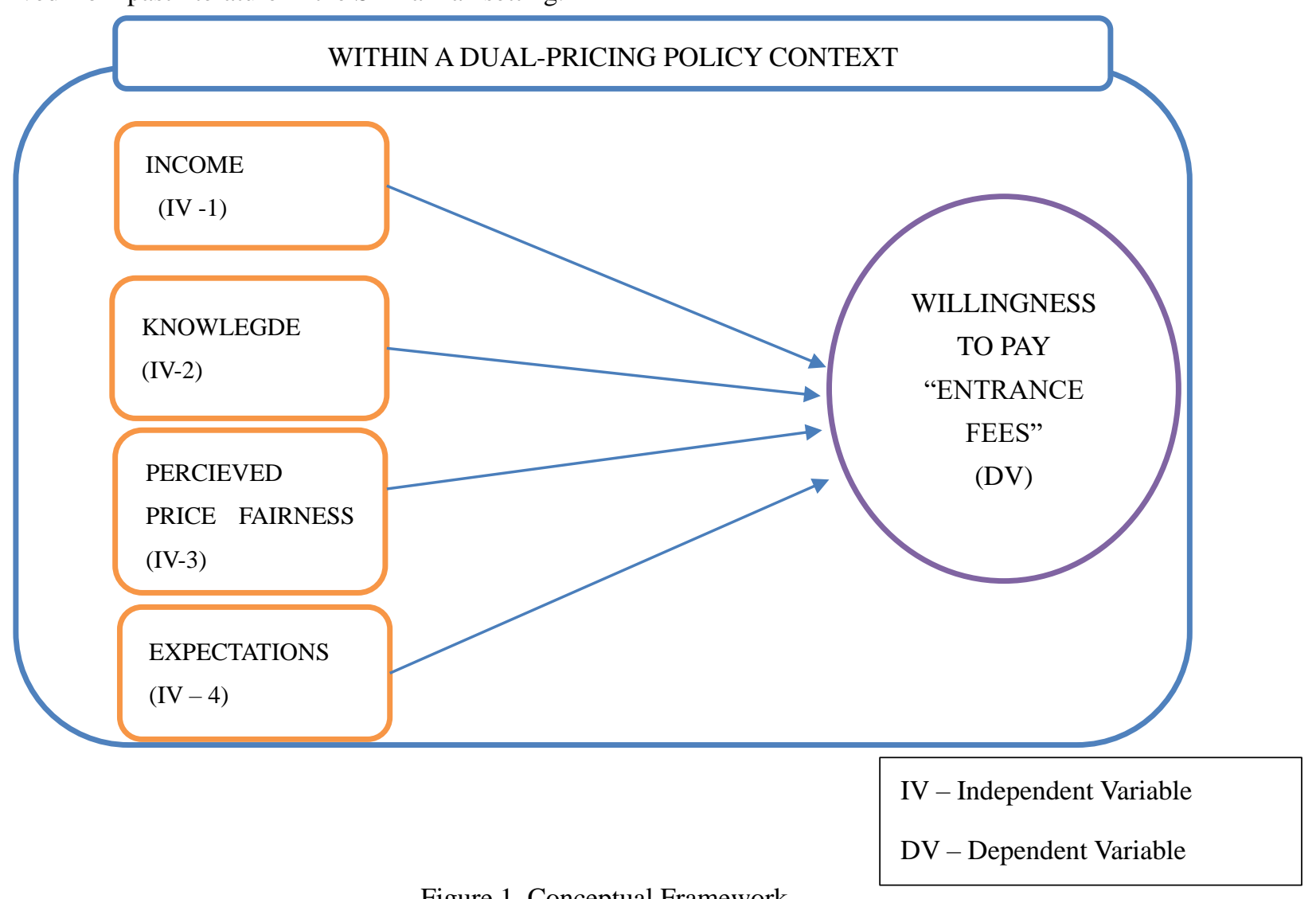

Figure 1. Conceptual Framework

Source: Author's illustration based on Literature (2019) 


\subsubsection{Willingness-to-pay}

Preceding literature suggests that willingness-to-pay has been tested in several ways worldwide, for a variety of research motives in different fields of studies. For this particular study, willingness-to-pay will be considered as the dependent variable (DV) in the proposed conceptual model. According to literature that focuses on user fees, WTP is one of the most frequently used DVs in the area of tourism research (Chung, J., Kyle, G., Petrick, J. and Absher, J. 2011).

The dual pricing of entrance fees to tourist's sites is carried out based on the assumption that foreign visitors are willing-to-pay more for entrance fees, has been debated that if non-residents can afford the money and time to travel the world for leisure activities, then they are most likely to be less sensitive to price (Mak, 2004). However, foreign holidaymakers disagree with the argument that the ability to pay and willingness-to-pay are two distinct concepts that should not be misinterpreted and used interchangeably.

Although WTP is distinguished from the reference price, it has often been used to indicate the maximum amount that consumers intend to pay. In tourism literature, WTP has been used to estimate the value of non-market goods (Chung et al., 2011).

Further, a recent study by Shultz, S., Pinazzo, J., and Cifuentes, M. (1998) applied the 'Contingent Valuation' method for estimating WTP for entrance fees at two national parks in Costa Rica. The study revealed that willingness-to-pay estimates for both the residents and foreign visitors were considerably higher than the actual fees paid. Thus, there exists an unclear grey area, if the DV would have behaved similarly or otherwise when tested within Sri Lanka along with the suggested independent variables (IV), i.e., indicated in the conceptual framework (Figure 1) as; IV-1, IV-2, IV-3, IV-4.

From a pricing perspective, Dharmaratne and Brathwaite (1998) have stated that money spent by a non-resident on a trip, i.e., hotel charges, airfare, or fuel costs, add up to form the total costs or composite price that becomes sunk costs once tourists get to the destination. This is when the sunk cost effect comes into play on consumption behavior. Sunk costs refer to the costs that have been incurred and cannot be recovered. Further research in the field of psychology and marketing have put forward the fact that consumer decision making is a portion of sunk costs, it is also considered as the human tendency to continue an attempt regardless of its advantages or value, once a monetary investment, effort, or time was put in (Arkes \& Blumer, 1985).

\subsubsection{Income}

As a tourist planning a trip, one of the main aspects considered is the expenses or the cost of the trip. Segments of the tourists visiting tourist attractions differ among categories such as locals, residents, and foreigners, while it is believed that the latter category has a higher willingness to pay (Apollo, 2014; Lindberg, 1991). Among the few reasons which justify the concept of dual-pricing used in countries, most foreign tourists have a higher disposal income, making the differed pricing levels appropriate (Apollo, 2014; Sandin, at el., 2010).

In a study conducted by Apollo (2014) using 162 respondents in the area of Kathmandu Valley, the income and budgeting aspect of foreign tourists were mapped out against the willingness to pay concerning the dual pricing concept. It revealed that nearly $22 \%$ of the foreign tourists spend up to one-tenth on the entry fees and as many as $60 \%$ of the local population; $41 \%$ of the foreign tourists were certain that the amount of the entry fee would not cause someone to cancel a visit, as according to them, tourists are willing to pay more while on holiday (Apollo, 2014).

Therefore, it is possible that the willingness-to-pay the entrance fees has an impact on the income of the tourists.

\subsubsection{Knowledge}

Sufficient justification is available when considering the possibility of visitors (foreign tourists) experiencing dual-pricing without their knowledge, which in turn, affects the willingness-to-pay. In a study carried out by Apollo (2014) using a sample population in Nepal, asked a simple question as to whether respondents are aware of the dual-pricing system. Many locals did reply in the affirmative along with a considerable amount of foreigners. Over half the tested individuals agreed to the price differentiation in a positive mindset, owing to the benefits gained from the said practice. However, it was not without a set of displeased respondents as well.

"More than half of the citizens and non-citizens agree with a higher fee (56\% and 61\% respectively), which will contribute to the economic development of the host country. However, more than one-third of the respondents (65\% and 33\% respectively) are displeased about it and disapprove of the dual pricing system"(Apollo, 2014).

Reynisdottir et al.,( 2008); Cordell and Johnson (1999) showed evidence that younger and highly educated individuals have a higher prominence to support the fee-paying policy for natural attractions. It is evident from 
the literature analyzed, that education plays an important role in the attitude of tourists on tourist sites. The likeliness of engagement with heritage and cultural locations improves with the level of education. Therefore, it is possible that the willingness-to-pay the entrance fees has an impact through the cultural education of tourists (Sharifi-Tehrani et al., 2013).

\subsubsection{Perceived Price Fairness}

In a generalized context or business terminology, perceived value is defined as the consumer's overall assessment of the utility, perception of what is received and what is given. As cited by Petrick (2004) in his writing, Zeithaml (1988) defines that value has four diverse meanings; value is the low price; whatever someone wants in a product, the quality that the consumer receives for the price paid, and what the consumer gets for what they pay.

Fairness of price or fees is initially referred to as a psychological perception of what is right or just in a particular setting (Chung et al., 2011). In the case of tourism, perceived price fairness is of no difference. A positive outcome was observed concerning the relationship between price fairness and willingness-to-pay (WTP), when empirically tested for public goods or services, including a university library, a campus beautification project (Chung et al., 2011). Interestingly, McCarville, Reiling, and White (1996) argued that while fair fees caught little public attention, unfair fees evoked considerable hostility and displacement.

Given the fact that tourism is one of the most non-price transparent industries, it would seem that price fairness perception should be examined about tourism (Chung \& Petrick, 2019). Literature in this avenue suggests that perceived fairness of price has been tested against willingness-to-pay and observed that the latter is positively related to perceived price fairness. Further, awareness of potential fee benefits would positively increase recreationists' response to user fees (Chung et al., 2011). Perceived Price Fairness or independent variable 3 (IV -3), in the setting of this study, is the perceived value of the destination in the mind of a tourist in contrast to the entrance fees charged on them. Hence, in the tourism industry, if a tourist's perception of performance or quality of a certain tourism product/service exceeds their expectations and the product/service represents good value for money, then tourists' perceptions of the quoted or listed price should be favorable (Asadi, Khazae, Pool, \& Reza Jalilvand 2014).

Furthermore, if tourists perceive the benefits offered by the tourism product/service relative to the perceived sacrifice (i.e. the price to be paid) is favorable, then tourists will be more likely to perceive that the price is fair (Asadi et al., 2014).

Therefore, perceived price fairness has an impact on willingness-to-pay the entrance fees.

\subsubsection{Visitor Expectations}

Customer expectations are defined as pre-trial beliefs about a product that serve as standards or reference points against which the product performance is judged upon (Zeithaml et al., 1993). According to Kaczynski \& Henderson (2008), understanding customer expectations and preferences and the benefits they seek is critical to marketers. Marketers and local businesses should aim to create on-site experiences that exceed expectations and delight tourists.

Khan (2003) has highlighted that some factors influence willingness-to-pay, for example, age, education level, and income; the desire to see, visit, and protect a particular park; and fulfillment of expectations. During the past decade, tourism received considerable attention in many aspects. As stated by Khan (2003), the global tourists flow often involves people from developed countries traveling to less developed countries or developing countries, to seek many experiences in traveling. Studies conducted in developing countries found that tourists have high expectations based on their travel needs (Cheung and Jim, 2013). Tourists' expectations of the type and quality of services to be offered in a particular destination are formed in their mindsets before the visit; the extent to which tourist expectations are met will eventually determine the level of tourist satisfaction (Akama and Kieti, 2003). Therefore, visitor expectations may have an impact on the willingness-to-pay the entrance fees.

Therefore, WTP considerably depends on Income, Knowledge, Perceived Price Fairness, and Visitor Expectations. These relationships (four hypotheses) are depicted in the conceptual framework (Figure 1).

\subsection{Collection and Measures}

\subsubsection{Sampling Design}

For this study, the sampling technique used was 'Purposive Sampling', following a mixed method deductive approach. As foreign tourists were surveyed using a questionnaire from key tourist attractions on the island selected based on the ease of access and approach. Latest information available on tourist arrivals to Sri Lanka 
reveals that 1,913,702 foreign tourists have arrived in Sri Lanka in the year 2019 (SLTDA Annual Report, 2019), and given the decrease of tourist arrivals into the country during the period of which this study was carried out, it was decided to adhere to Convenient Sampling method. The number of subjects; the sample size was 150 elements. A considerable number of previous researches were identified to have used a sample size within a similar range of respondents.

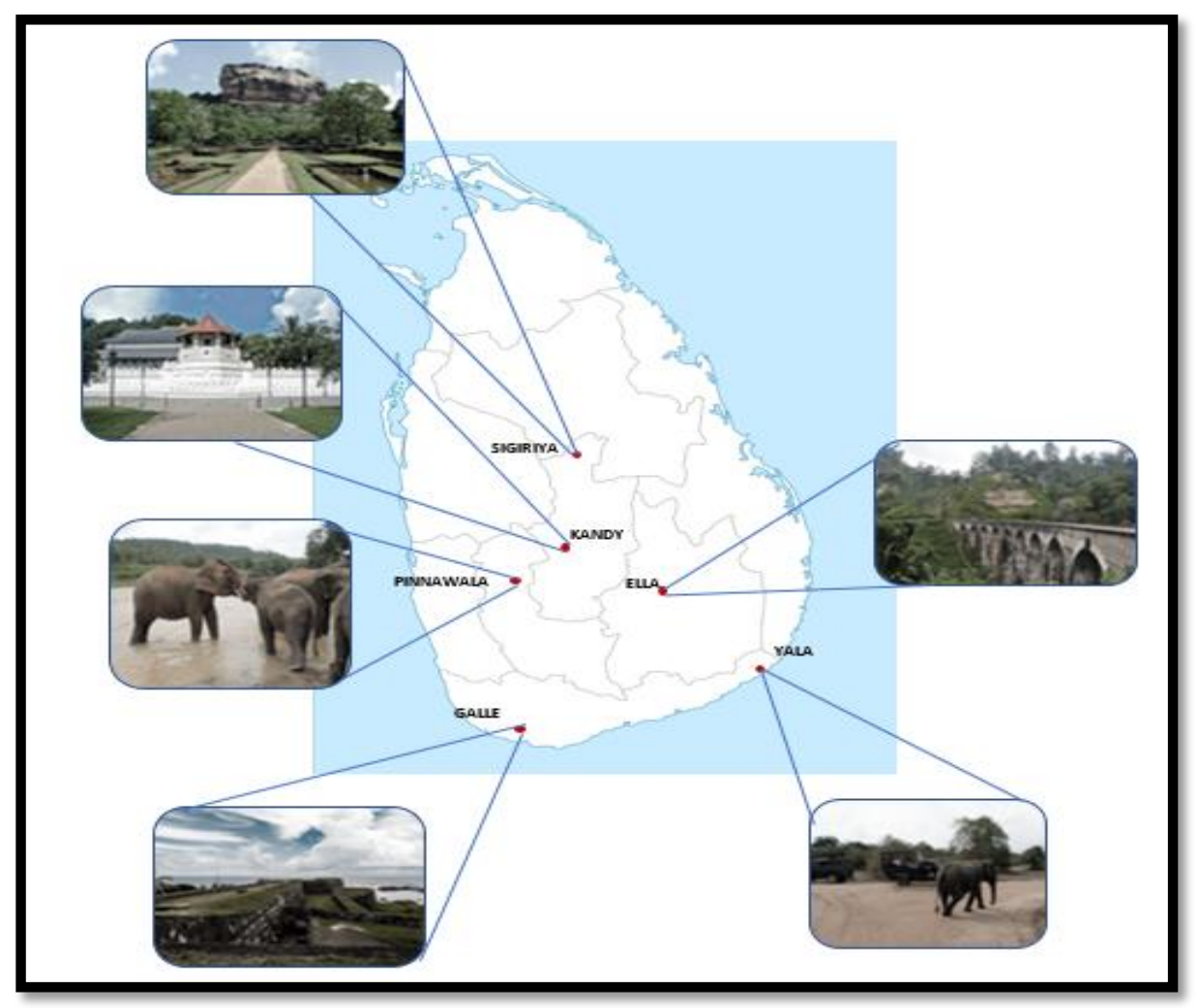

Figure 2. Data Collection Points

\subsubsection{Method of Data Collection}

The medium of collecting data was through the questionnaire distributed among the foreign tourists selected based on Convenience Sampling (availability and ease of access). However, to carry out the survey, locations where the availability of foreign tourists, is generally high were selected. These locations are shown in Figure 2.

\subsubsection{Assessment of Reliability and Validity of the Constructs}

This study involves four IVs that have been measured on a five-point Likert scale where a value of 1 represents 'Strongly Disagree' and value 5 indicates 'Strongly Agree' to the statement. The DV was measured separately as a monetary value. Thus, to establish the reliability and validity of the final data set, a Cronbach's Alpha test and factor analysis, 'Principal Component Extraction' were conducted for each IV.

Thus, internal consistency, adequate sampling, and an acceptable level of representation of variance were observed in all the constructs used, through reliability and validity testing. Therefore, all the variables (Income, Knowledge, Perceived Price Fairness, and Visitor Expectations) were used for further analysis in the study

\section{Results}

The profile of the respondents of the sample is given in Table 3. A large portion (67\%) of foreign visitors of the sample is from the Western European countries and more than 50\% in the sample belonged to the age category between $26-35$ years whilst the scenic beauty of the country was the major reason for visiting the country representing $46 \%$ of the sample. The majority representing $29 \%$ of the sample belonged to the category of annual disposable income between US\$26,000 - 35,000 and the expected single site visit fee expected to pay was between US $\$ 5-10$ and US\$ $10-15$ by $30 \%$ and $28 \%$ respectively. A marginally higher percentage of females $(53 \%)$ and $47 \%$ of males represented the sample. 
Table 3. Respondent's profile

\begin{tabular}{|c|c|c|}
\hline & Frequency & Percentage \\
\hline \multicolumn{3}{|l|}{ Region } \\
\hline North America & 10 & $6.66 \%$ \\
\hline South America & 3 & $2.00 \%$ \\
\hline Western Europe & 100 & $66.66 \%$ \\
\hline Eastern Europe & 12 & $8.00 \%$ \\
\hline Middle East & 5 & $3.33 \%$ \\
\hline South Asia & 6 & $4.00 \%$ \\
\hline East Asia & 10 & $6.66 \%$ \\
\hline Oceania & 4 & $2.66 \%$ \\
\hline \multicolumn{3}{|l|}{ Gender } \\
\hline Male & 71 & $47.33 \%$ \\
\hline Female & 79 & $52.66 \%$ \\
\hline \multicolumn{3}{|l|}{ Age Category } \\
\hline $16-25$ & 42 & $28.00 \%$ \\
\hline $26-35$ & 79 & $53.00 \%$ \\
\hline $36-45$ & 13 & $8.66 \%$ \\
\hline $46-55$ & 6 & $4.00 \%$ \\
\hline $56-65$ & 10 & $6.66 \%$ \\
\hline \multicolumn{3}{|c|}{ Reason for choosing Sri Lanka as a Destination } \\
\hline Affordability & 17 & $11.33 \%$ \\
\hline Scenic Beauty & 69 & $46.00 \%$ \\
\hline Culture \& Tradition & 33 & $22.00 \%$ \\
\hline \multicolumn{3}{|l|}{ Exploration } \\
\hline Sea, Sun \& Sand & 13 & $8.66 \%$ \\
\hline Other & 18 & $12.00 \%$ \\
\hline \multicolumn{3}{|c|}{ Expected spending on a single site entrance fee } \\
\hline 1-4 USD & 4 & $2.66 \%$ \\
\hline 5-10 USD & 46 & $30.66 \%$ \\
\hline 11-15 USD & 42 & $28.00 \%$ \\
\hline 16-20 USD & 19 & $12.66 \%$ \\
\hline 21-25 USD & 15 & $10.00 \%$ \\
\hline 26-30 USD & 10 & $6.66 \%$ \\
\hline 31-35 USD & 2 & $1.33 \%$ \\
\hline 36 USD & 12 & $8.00 \%$ \\
\hline \multicolumn{3}{|c|}{ Annual Disposable Income } \\
\hline 1000 - 5000 USD & 17 & $11.33 \%$ \\
\hline 6000 - 15000 USD & 15 & $10.00 \%$ \\
\hline $16000-25000$ USD & 21 & $14.00 \%$ \\
\hline 26000 - 35000 USD & 44 & $29.33 \%$ \\
\hline 36000 - 45000 USD & 17 & $11.33 \%$ \\
\hline 46000 - 55000 USD & 13 & $8.66 \%$ \\
\hline $56000-65000$ USD & 10 & $6.66 \%$ \\
\hline $66000 \mathrm{ABOVE}$ & 13 & $8.66 \%$ \\
\hline
\end{tabular}

\subsection{Correlation Analysis}

To achieve the second objective of this study, which was 'to study the relationship between each variable with willingness-to-pay', a correlation analysis was conducted. A Pearson correlation coefficient was tested between each independent variable (Income; Knowledge; Perceived Price Fairness; Visitor Expectations) and the dependent variable (Willingness-to-pay) to test the validity of the hypothesis in this study. Table 4 below shows the Pearson Correlation results of the variables. 
Table 4. Pearson Correlation Coefficients

\begin{tabular}{lccccc}
\hline & & Income & Knowledge & PPF & VE \\
\cline { 2 - 7 } WTP & Pearson Correlation & $.721^{* * *}$ & $.808^{* * *}$ & $.775^{* *}$ & $.862^{* * *}$ \\
& Sig. (2-tailed) & .000 & .000 & .000 & .000 \\
& $\mathrm{~N}$ & 150 & 150 & 150 & 150 \\
\hline
\end{tabular}

Source: Author's calculation

\subsubsection{Correlation between Income (IV-1) and Willingness-to-pay (DV)}

Based on Table 4 representing coefficients extracted from SPSS output, Income, IV-1 is significant to predict Willingness-to-pay (DV) in this study. Statistical calculations show a p-value of .000 which is within the standard significance level of alpha ( $\mathrm{p}>.05)$. Hence, the null hypothesis is rejected. Further, the results indicate that Pearson Correlation (R-value) is .721 which represents that there is a strong positive relationship between IV-1 and the DV.

\subsubsection{Correlation between Knowledge (IV-2) and Willingness-to-pay (DV)}

This study aims to uncover the relationship between Knowledge and WTP, therefore the following hypothesis was tested to assess the association among the two, i.e., IV-2 and DV in a dual-pricing situation.

Based on Table 4 (Coefficients), p-value of the relationship is .000 which is less than alpha value 0.05 [significant level of .040 (p>0.05)]. Thus, Knowledge is a significant variable to predict Willingness-to-pay (DV). Since there is a relationship between Knowledge (IV-2), and Willingness-to-pay (DV). Moreover, the result shows that Pearson Correlation (R-value) is .808 indicating a strong positive relationship between this IV-2 and the DV.

\subsubsection{Correlation between Perceived Price Fairness (IV-3) and Willingness-to-pay (DV)}

Based on Table 4, Perceived Price Fairness (IV-3) shows a significance value of .000 when tested with the DV. Since the p-value falls within the permitted threshold of 0.05 , it was concluded that IV-3 is a significant predictor of Willingness-to-pay (DV) in this study. Further, Pearson Correlation (R-value) of .775 indicates a strong positive relationship between IV-3 and the DV.

\subsubsection{Correlation between Visitor Expectation (IV-4) and Willingness-to-pay (DV)}

Based on Table 4 (Coefficients), Visitor Expectation proved to be a significant predictor of willingness-to-pay (DV) in this setting. This is because p-value is 0.032 which is lower than alpha value 0.05 [significant level of (p>0.05)]. Therefore, H0 will be rejected and $\mathrm{H} 1$ is accepted since there is a relationship between Visitor Expectation and Willingness-to-pay. Pearson Correlation (R-value) of this association is .862 demonstrating a strong positive relationship.

\subsection{Multiple Regression Analysis}

Multiple Linear Regression analysis was used to achieve the third objective of this study. The objective aims to evaluate the impact of the identified variables on willingness-to-pay dual-priced entry fees of foreign travelers in Sri Lanka.

According to Uyanık and Guler (2013), regression models with one DV and several IVs are known as multivariate or multiple regression models. Assumptions of multiple regression analysis are such that, data to be free from extreme values, linearity, to have a normal distribution and have no multiple ties among the IVs.

Table 5. Results of Model Summary

\begin{tabular}{ccccc}
\hline Model & $\mathrm{R}$ & R Square & Adjusted R Square & $\begin{array}{c}\text { Std. error of the } \\
\text { Estimate }\end{array}$ \\
\hline 1 & $.892^{\mathrm{a}}$ & .796 & .790 & 2.37972 \\
\hline
\end{tabular}

Predictors: (Constant), INCOME, KNOWLEDGE, PPF, VE

Dependent Variable: WTP

Source: Authors' calculation based on Survey data (2019)

As shown in Table 5, the adjusted $\mathrm{R}$ square value of the regression model is 0.790 , hence $79 \%$ of the variations in willingness-to-pay (DV) is represented by the IVs, IV-1, IV-2, IV-3, and IV-4, respectively; Income, Knowledge, Perceived price fairness, and Visitor expectations in the dual-pricing condition. 
Table 6. Results of ANOVA

\begin{tabular}{llrrrrr}
\hline Model & & Sum of Squares & df & Mean Square & \multicolumn{1}{c}{ F } & \multicolumn{1}{c}{ Sig. } \\
\hline 1 & Regression & 3203.231 & 4 & 800.808 & 141.409 & $.000^{\mathrm{b}}$ \\
& Residual & 821.143 & 145 & 5.663 & & \\
& Total & 4024.373 & 149 & & & \\
\hline
\end{tabular}

Dependent Variable: WTP

Predictors: (Constant), VE, INCOME, PPF, Knowledge

According to the results shown in Table 6, the P-value of the model is 0.000 , which is less than 0.001 . The model appears to be significant with at least one independent variable in the model.

Table 7. Results of Regression Model Coefficients

\begin{tabular}{|c|c|c|c|c|c|c|}
\hline & & Unstanc & oefficients & $\begin{array}{l}\text { Standardized } \\
\text { Coefficients }\end{array}$ & & \\
\hline & Model & B & Std. Error & Beta & $\mathrm{t}$ & P-value \\
\hline 1 & (Constant) & -8.267 & .822 & & -10.056 & .000 \\
\hline & INCOME & .826 & .380 & .128 & 2.171 & .032 \\
\hline & Knowledge & .860 & .480 & .140 & 1.790 & .076 \\
\hline & PPF & 1.318 & .388 & .217 & 3.401 & .001 \\
\hline & VE & 3.300 & .486 & .491 & 6.783 & .000 \\
\hline
\end{tabular}

Source: Authors' calculation based on Survey data (2019)

As per Table 7, the regression model coefficients can be interpreted as follows. The significance level or $\mathrm{P}$ value of Income (IV-1) is 0.032 which is considered to be significant as it is below the accepted threshold of 0.05 . The beta value of Income is 0.826 , hence IV-1 holds a strong positive impact on willingness-to-pay, indicating that an increase of one unit in Income will result in a 0.826 increase in the willingness-to-pay.

P-value of Knowledge (IV-2) has proved to be an insignificant variable with 0.076 significance level, which is beyond the accepted threshold of 0.05 . Although the beta value of 0.860 denotes a strong positive relationship between IV-2 and DV, the variable is deemed to be insignificant, thus, not a reliable predictor.

Perceived Price Fairness (IV-3) has proved to be a significant predictor with a P-value of 0.032, which is well within the accepted range. Further, the beta value of this IV is 1.318 . Thus, PPF has a positive impact on willingness-to-pay. An increase in one unit of PPF will in turn generate a 1.318 increase in DV.

The P-value of Visitor expectations (IV-4) is at 0.000 , hence, it is considered to be a highly significant variable. Beta value stands at 3.300, indicating a strong positive impact on the dependent variable in the regression model. The results demonstrate that Visitor Expectation has a high impact on willingness-to-pay in this context. As such, after the regression analysis, the following equation was derived.

$$
W T P=-8.267+0.826(I N C)+1.318(P P F)+3.3(V E)
$$

\subsection{Thematic Analysis}

The fourth and final objective of the study was achieved through a thematic analysis. The objective was to understand the perceptions of foreign tourists on the dual-pricing concept and its' application. The qualitative study adopted a template-based theme for identification and discussion on the derived themes, in contrast with the research issue and literature. The analysis comprises of a template analysis - in which the idea is discussed with a template, or an order, in which the opinions were categorized.

\begin{tabular}{|ll|}
\hline 1. & Agree to pay a high price \\
2. & Transparency and visibility of the information \\
3. & Extremely high prices should not be charged \\
4. & The dual-pricing gap should be reasonable \\
5. & The invested amount should go into sustainable initiatives \\
\hline
\end{tabular}

Figure 2. Template for thematic analysis

Source: Authors' compilation 


\subsubsection{Agree to Pay a Higher Price}

Upon analyzing foreign visitors' consent to pay a higher price than the locals to visit the Sri Lankan tourist sites, the majority of the respondents agreed with the idea to accept a differentiated higher price for entrance. It was observed that these tourists were quite understanding of this factor based on several avenues. Firstly, they have identified that the Sri Lankan economy is not as strong as economies of their own home countries. Therefore, charging a different (Higher) price from the tourists can be easily justified.

A few responses are, "I understand the concept of dual pricing benefits the locals. I feel that the locals shouldn't have to pay what tourists pay. However, in my home country, we do not get a discount when visiting national parks or monuments. However, I agree with the concept but to a certain extent at the price gap" (Respondent 127). "I believe that this is a good thing because generally, the rupee is a lot cheaper for foreigners than it is when locals earn, therefore this gets balanced out" (Respondent \#98).

"I understand the need for dual pricing; it creates benefits and promotes local tourism as well as increasing revenue via tourism" (Respondent \#03). "In my opinion, it is reasonable to accept dual-pricing in a country such as Sri Lanka to help tourism" (Respondent \#93).

\subsubsection{Transparency and Visibility of the Information}

When it comes to dual-pricing - although the majority of tourists have identified the need for this pricing concept to be in operation, they tend to expect better information. Mainly, information about the differential pricing mechanism is expected to be shared with the tourists. This is a key area where the respondents could be convinced that they are not being exploited.

Some responses are, "Dual pricing is okay. But it's better to have more information lockets with all the information about prices. So then there will be no arguments and misunderstanding about prices". (Respondent \#134)

"I think it would be helpful if there was more information at each major site, explaining the difference between fees and why. It took me several days to learn that Sri Lankans pay less, and because it isn't explained upfront, it can make tourists feel like maybe they are being tricked or cheated" (Respondent \#64).

\subsubsection{Extreme Prices Should not Be Charged (Negative Perception)}

Although the popular statement of the respondents was that they were willing to pay a higher price for the visits - they all emphasized the fact that there should not be a massive gap between the prices they pay and what is charged from locals. This is mainly stemmed when it comes to the developed countries - there are no discounted prices for the visitors, be it foreigners or locals - but a single flat rate system is provided. Hence, with these levels of standards - even though the tourists are willing to pay a higher price they are not willing to pay an extremely high fee.

With much concern, they stated their opinion on this unpopular practice: "I understand there is a gap between local and tourist, but it shouldn't be too big. However, I do think that some locations like Sigiriya Lion rock are overpriced which makes it less available to the foreign tourists with lower salaries" (Respondent \#116).

\subsubsection{The Dual-Pricing Gap Should Be Reasonable (Positive Perception)}

On the other hand, there were discussions where some of the tourists felt that there should be dual pricing with a reasonable gap. They have not developed a negative perception about the country, regarding the high level of the gap between the locals and the tourist's entrance fees for tourists' sites. They tend to see it in a much more favorable manner as an issue to be addressed in terms of the development of the industry.

A few responses are, "To me as a foreigner, it's acceptable to pay more than the locals, especially at religious and cultural sites, which are important for locals. Sri Lankan people should be able to experience and learn about their culture and religion of their country no matter what their income is. And as tourists, I am more than okay to help to ensure this by paying more" (Respondent \#105).

"I am unsure if I will do it due to the high cost of this attraction. Dual-pricing can be beneficial for the host country as long as it doesn't discourage the tourists from visiting the attractions" (Respondent \#102).

\subsubsection{The Invested Amount Should Go into Sustainable Initiatives}

This was one of the most crucial opinions expressed by tourists. Considering the demography of the travelers, it was established that they are 'informed travelers'. Hence, paying an extra amount of money, and adhering to the dual pricing policy - they expect it to be reflected through tangibles, i.e., the revenue generated to be put into maintenance and systematic development of the destinations with time. 
Thus, considering different opinions expressed by the foreigners - it is evident that there is a need for tourists to see that their fees are being used for a sustainable venture, especially in terms of building the country. One of the most observable traits was that the respondents were not thinking about the individual comfort but fees they pay will have to be utilized in improving facilities of at the tourist's sites.

According to opinions raised by these respondents: "I don't mind paying a little extra, two points to consider, 1 . Do not make it a huge difference. 2. Tell me where my dollars are going and how it's helping" (Respondent \#29).

"Toilets, security, roads, traffic. All those things must be improved; also understand that the money generated by tourism will help the growth/ development of the attractions/ country in the long run" (Respondent \#34).

\section{Discussion}

In evaluating the findings of the quantitative statistical analysis in this study, the literature review emphasizes the different relationships observed about Income, Knowledge, Perceived price fairness, Visitor expectation when testing willingness-to-pay in different contexts. Further, the same concept had been tested with many other explanatory variables and different frameworks at various instances leading to different results that were in line with respective samples and settings.

According to Sharifi-Tehrani et al. (2013), Income was a key determinant of willingness to pay in a dual-pricing condition, where a strong positive relationship was witnessed in a sample of 573 respondents (foreign and local) in Iran. As stated by Cheung and Jim (2013), significant positive relationships were found with Knowledge, Income, and Visitor expectations when tested for WTP among 1500 nature and general tourists in Hong Kong. In a study carried out by Chung et al. (2011) to evaluate attitudes towards user fees among tourists in the United States of America, 1310 respondents were tested for perceived price fairness with WTP. These scholars concluded that PPF was positively related to WTP.

\subsection{Income}

This study concluded that income and willingness-to-pay in the setting of a dual-priced entry fee was a key predictor with a positive impact on the latter. It was observed that foreigners from high-income nations or developed countries were not hesitant to pay differentiated high prices for entrance at tourists' sites, yet tourists from countries/regions similar to Sri Lanka were only willing to tolerate a lower level of the dual-pricing gap. Literature compiled for the research had proved that the income level is one of the most widely used predictors of WTP, but mixed results have been obtained (Young et al., 2011).

\subsection{Knowledge}

Knowledge tested in this study context was deemed to be aligned with the findings of previous studies, where the IV showed a strong positive correlation with WTP. According to Crompton (1987) and Reiling et al. (1998), proving a potential consumer with accurate and adequate information about costs related to a particular activity makes them more likely to accept a given price. As a result of becoming more knowledgeable about what they are charged for, thus, increases their WTP. Although, when tested for the impact on WTP together with the other three IVs, i.e. Income, Perceived price fairness, and Visitor Expectations; Knowledge (IV-2) turned out to be insignificant in predicting WTP, thus, it was dominated by IV-1, IV-3, and IV-4. The reason for this can be a change in the study context.

\subsection{Perceived Price Fairness}

The result related to Perceived Price Fairness was consistent with the findings of previous works by scholars. As stated by Asadi et al. (2014), if the benefits offered by the tourism services are highly relative to the perceived sacrifice (i.e. the price to be paid), then tourists will be more likely to perceive that the price is reasonable. Thus, this increases their WTP. Similar findings were observed in this study where tourists with a higher level of agreement to perceived price fairness showed higher willingness-to-pay dual-priced entrance fees.

\subsection{Visitor Expectations}

Visitor Expectations of foreign tourists with regards to tourists' destinations were a significant determinant of willingness to pay dual-priced entrance fees, according to this study. A high correlation was observed between the predictor and WTP. The findings are in agreement with previous studies, though the contexts are remarkably distinct. Cheung and Jim, (2013) have found that expectations of tourists indicated a significant positive relationship with the willingness-to-pay for entrance fees. Thus, tourists with high expectations of the destination are more willing-to-pay a higher enhanced fee despite price differentiation. In turn, these tourists expected a high-quality experience that is worth their monetary sacrifice. 


\subsection{Perception of the Visitors}

Based on the findings the thematic analysis in this study, the main concerns identified were that while many foreign tourists have understood the fact that they have to pay a higher fee to enter tourists' sites, but if they were to pay the premium prices - in return, they would demand better and quality infrastructure. To avoid any unfair judgment, the availability of information and transparency of pricing was a key determinant. However, large dual-pricing gaps were driving tourists away, as large gaps were considered discriminatory and unfair. Therefore, the major contribution of this learning is to potentially reduce the negative perceptions of foreign tourists while adopting a dual-pricing policy, by paying attention to their concerns as visitors. Moreover, to propose amendments to the existing differential-pricing system to cancel-out any unreasonable discrimination towards the non-residents, to allow them a more satisfying experience within Sri Lanka as a top-notch tourist destination.

\section{Limitations, Future Research, and Conclusion}

\subsection{Limitations}

Certain constraints were encountered in carrying out this study. The main limitation was the coverage error, i.e. the data collection sites were limited to only six destinations due to certain constraints. Moreover, purposive sampling instead of stratified sampling that best serves the research purpose, had to be adopted for data collection. This was due to the unanticipated Easter Sunday terror attack (2019) in Sri Lanka that took place during the period in which this study was conducted, which led to a drastic reduction of the tourist inflow to the country.

Since the target population was foreigners, conversing with tourists from different countries was another difficulty faced due to language differences. Lack of competency in English on the part of tourists made some potential respondents unable to fill out survey forms, while another group of travelers disliked sacrificing their leisure time on filling a questionnaire, which was some hardships faced.

The above-discussed factors could be considered as limitations on data collection and interpreting the outcomes of the study. Even though with the existence of such barriers, required data collection was achieved through an adequate sample efficiently through the semi-structured questionnaire, for the analysis.

\subsection{Further Research}

The researchers identified certain avenues for future research from the findings and limitations of this study. This study was conducted to determine foreign traveler's willingness to pay dual-priced entry fees for any tourist site in Sri Lanka. The scope of a future study could be narrowed to a specific tourist attraction where a significant price-duality could be recognized. The results of such a study could find the best price that should be set as the entry fee at a particular site, which benefits both the travelers and relevant authorities. Moreover, there exists a vast range of determinants that predict the tested DV, apart from the ones used in this study, hence a different set of variables could be adopted for future research.

\subsection{Conclusion}

The primary focus of this paper is on the foreign tourist's willingness-to-pay (WTP) entrance fees at tourist destinations in Sri Lanka under the dual-pricing policy and to gain an understanding of tourist perception of adopting such a pricing mechanism in Sri Lanka. Hence the following objectives were identified and achieved through the research.

1. Determining the factors that affect foreign traveler's willingness-to-pay entrance fees at tourist attractions.

2. Identifying the relationship between each variable with willingness-to-pay.

3. Evaluating the impact of the identified variables on willingness-to-pay of foreign travelers.

4. Understanding the perception of foreign tourists on the dual-pricing concept and its application.

The four factors, Income, Perceived Price Fairness, Knowledge, and Visitor Expectations were identified and these four factors were significantly and positively co-related to WTP further, except Knowledge's other three factors had a significant impact on their WTP. The Visitor Expectation had the highest impact over willingness-to-pay in this context.

The price elasticity was different among visitors. Therefore, a combination of pricing and non-pricing strategies that accomplish expectations of foreign visitors at tourist sites will be favorably accepted by foreign travelers which ultimately creates a positive image about the country as a tourist destination around the world.

The act of price differentiation for local and foreign tourists requires attention from the authorities and various 
business sectors related to the tourism industry of Sri Lanka. Negligence on this would create a negative ideology on foreign travelers that this practice is unethical and may ultimately affect a tourist's decision (adversely) to choose Sri Lanka as a travel destination. Successful strategy implementations that enhance the productivity of both the visitors and governing authorities will bring out the solutions for this existing issue. Outcomes of this study will be of value to implement policy decisions and propose amendments to existing policies for more sustainable tourism especially with the outbreak of COVID 19 epidemic and post COVID effect for countries like Sri Lanka which have a substantial contribution to their economies from the tourist industry. The tourism industry is the third-largest contributor to Sri Lanka's GDP, and the tourists' arrivals to the country have been increasing at an annual rate of $22 \%$ during the past five years. The area of focus in this study is expected to provide valuable insights into the many stakeholders of the said industry. The case of dual-pricing or discriminatory pricing for entrance tickets at tourists' sites is a topic discussed at the global level which has been criticized in public platforms by a majority of global travelers. Hence, the findings of this study would be useful for the relevant authorities and beneficiaries of the tourism sector, in dealing with any negative image/perception that may arise in the country due to this DP policy and therefore, to adopt a more sustainable pricing mechanism that tourists would prefer.

\section{References}

Akama, J., \& Kieti, D. (2003). Measuring tourist satisfaction with Kenya's wildlife safari: a case study of Tsavo West National Park. Tourism Management, 24(1), 73-81. https://doi.org/10.1016/S0261-5177(02)00044-4

Apollo, M. (2014). Dual Pricing - Two Points of View (Citizen and Non-citizen) Case of Entrance Fees in Tourist Facilities in Nepal. Procedia - Social and Behavioral Sciences, 120, 414-422. https://doi.org/10.1016/j.sbspro.2014.02.119

Arkes, H., \& Blumer, C. (1985). The psychology of sunk cost. Organizational Behavior and Human Decision Processes, 35(1), 124-140. https://doi.org/10.1016/0749-5978(85)90049-4

Asadi, A., Khazaei Pool, J., \& Reza Jalilvand, M. (2014). The effect of perceived price fairness through satisfaction and loyalty on international tourists' price acceptance of Islamic-Iranian art products. Education, Business, and Society: Contemporary Middle Eastern Issues, 7(4), 201-215. https://doi.org/10.1108/EBS-10-2013-0045

Bankok Post, L. (2012). Double prices deter tourists. Retrieved from https://www.bangkokpost.com/opinion/opinion/469664/double-prices-deter-tourists

Bolton, L., Warlop, L., \& Alba, J. (2003). Consumer Perceptions of Price (Un) Fairness. Journal of Consumer Research, 29(4), 474-491. https://doi.org/10.1086/346244

Cheung, L., \& Jim, C. (2013). Expectations and willingness-to-pay for ecotourism services in Hong Kong's conservation areas. International Journal of Sustainable Development \& World Ecology, 21(2), 149-159. https://doi.org/10.1080/13504509.2013.859183

Chung, J., \& Petrick, J. (2019). Price Fairness of Airline Ancillary Fees: An Attributional Approach - Jin Young Chung, James F. Petrick, 2013. https://doi.org/10.1177/0047287512457261

Chung, J., Kyle, G., Petrick, J., \& Absher, J. (2011). Fairness of prices, user fee policy, and willingness to pay among visitors to a national forest. Tourism Management, 32(5), 1038-1046. https://doi.org/10.1016/j.tourman.2010.08.016

Cohen, E. (1972). Towards a sociology of international tourism. In Social Research. Social Research, 39(1), 164-182.

Cordell, O., \& Johnson, D. (1999). Downtowns: Revitalizing the Centers of Small Urban Communities. Retrieved from http:1/wwwcitylafayette.inns/features/hist_frames.htm City of New Cordell, Oklahoma

Crompton, J., \& Jeong, J. (2016). Experiments Testing the Effectiveness of Purposeful Anchoring on Reference Price in the Context of Public Leisure Services. Journal of Leisure Research, 48(4), 307-326. https://doi.org/10.18666/JLR-2016-V48-I4-6535

Crompton, Rosemary. 2003. Consumption and class analysis. In The Consumption reader, edited by D.B. Clark, M.A. Doel and K.M L. Housiaux. London; New York: Routledge.

Dharmaratne, G., \& Brathwaite, A. (1998). Economic Valuation of the Coastline for Tourism in Barbados. Journal of Travel Research, 37(2). 138-144. https://doi.org/10.1177/004728759803700205

Howard, R. (2009). Risky business? Asking tourists what hazards they encountered in Thailand. Tourism 
Management, 30(3), 359-365. https://doi.org/10.1016/j.tourman.2008.08.007

Kaczynski, A. T., \& Henderson, K. A. (2008). Parks and recreation settings and active living: a review of associations with physical activity function and intensity. J.Phys Act Health 2008, 5, 619-632. https://doi.org/10.1123/jpah.5.4.619

Khan, M. (2003). ECO SERV. Annals of Tourism Research, 30(1), 109-124. https://doi.org/10.1016/S0160-7383(02)00032-4

Lindberg, K. (1991). Policies for Maximising Nature Tourism's Ecological and Economic Benefits. World Resources Institute, Washington, DC.

Mak, J. (2004). Tourism and the economy: understanding the economics of tourism. Choice Reviews, 4l(08), 41-4780-41-4780. https://doi.org/10.5860/choice.41-4780

McCarville, R., \& Crompton, J. (1987). An Empirical Investigation of the Influence of Information on Reference Prices for Public Swimming Pools. Journal of Leisure Research, 19(3), 223-235. https://doi.org/10.1080/00222216.1987.11969689

McCarville, R., Reiling, S., \& White, C. (1996). The role of fairness in users' assessments of first-time fees for a public recreation service. Leisure Sciences, 18(1), 61-76. https://doi.org/10.1080/01490409609513272

Murphy, P., Pritchard, M., \& Smith, B. (2000). The destination product and its impact on traveler perceptions. Tourism Management, 21(1), 43-52. https://doi.org/10.1016/S0261-5177(99)00080-1

Pearce, P. (2005). Themes and conceptual schemes. Aspects of Tourism. Tourist Behaviour, pp. 241. https://doi.org/10.21832/9781845410247

Perdue, R. (2002). Perishability, Yield Management, and Cross-Product Elasticity: A Case Study of Deep Discount Season Passes in the Colorado Ski Industry. Journal of Travel Research, 41(1), 15-22. https://doi.org/10.1177/0047287502041001003

Petrick, J. (2004). First Timers' and Repeaters' Perceived Value. Journal of Travel Research, 43(1), 29-38. https://doi.org/10.1177/0047287504265509

Reeves, C., \& David, A. B. (1995). Quality as Symphony. Cornell Hospitality Quarterly, 36(3), 72-79. https://doi.org/10.1177/001088049503600323

Reynisdottir, M., Song, H., \& Agrusa, J. (2008). Willingness to pay entrance fees to natural attractions: An Icelandic case study. Tourism Management, 29(6), 1076-1083. https://doi.org/10.1016/j.tourman.2008.02.016

Samdin, Z., Abdul Aziz, Y., Radam, A., \& Yacob, M. (2010). Factors Influencing the Willingness to Pay for Entrance Permit: The Evidence from Taman Negara National Park. Journal of Sustainable Development, 3(3). https://doi.org/10.5539/jsd.v3n3p212

Sharifi-Tehrani, M., Verbič, M., \& Chung, J. Y. (2013). An analysis of adopting dual pricing for museums: the case of the national museum of Iran. Annals of Tourism Research, 43, 58-80. https://doi.org/10.1016/j.annals.2013.04.001

Shultz, S., Pinazzo, J., \& Cifuentes, M. (1998). Opportunities and limitations of contingent valuation surveys to determine national park entrance fees: evidence from Costa Rica. Environment and Development Economics, 3(1), 131-149. https://doi.org/10.1017/S1355770X98000072

Sri Lanka Tourism Development Authority. (2019). Annual Statistical Report. Retrieved from http://www.sltda.lk/node/763

Uyanık, G., \& Güler, N. (2013). A Study on Multiple Linear Regression Analysis. Procedia - Social and Behavioral Sciences, 106, 234-240. https://doi.org/10.1016/j.sbspro.2013.12.027

Walpole, M. J., Goodwin, H. J., \& Kari, G. R. W. (2011). Pricing Policy for Tourism in Protected Areas: Lessons from Komodo National Park, Indonesia. Conservation Biology, 15(1), 218-227. https://doi.org/10.1111/j.1523-1739.2001.99231.x

World Tourism Organization. (2020). Methodological Notes to the Tourism Statistics Database, 2020 Edition, UNWTO, Madrid. https://doi.org/10.18111/9789284421473

Wu, M. Y., Wall, G., \& Zhou, L. (2014). A free pricing strategy at a major tourist attraction: The Case of West Lake, China. Journal of Destination Marketing \& Management, 3(2), 96-104. https://doi.org/10.1016/j.jdmm.2014.01.002 
Young, C., Gerard, T, K., \& James F. P. (2011). Fairness of prices, user fee policy, and willingness to pay among visitors to a national forest. Tourism Management, 32, 1038-1046. https://doi.org/10.08.016

Zeithaml, V. (1988). Consumer Perceptions of Price, Quality, and Value: A Means-End Model and Synthesis of Evidence. Journal of Marketing, 52(3), 2-22. https://doi.org/10.2307/1251446.

\section{Copyrights}

Copyright for this article is retained by the author(s), with first publication rights granted to the journal.

This is an open-access article distributed under the terms and conditions of the Creative Commons Attribution license (http://creativecommons.org/licenses/by/4.0/). 